\title{
LUCCHESI, Marco. Cultura da Paz. Rio de Janeiro: Oficina Raquel, 2020. 204p.
}

\author{
Dárcia Fusaro \\ Doutora em Comunicação e Semiótica (PUC-SP); \\ Pós-doutoramento em Artes (UNESP) \\ São Paulo/SP/Brasil \\ profmarciafusaro@gmail.com \\ (i) Moisés Galvão Batista \\ Mestrando em Gestão e Práticas Educacionais (UNINOVE) \\ São Paulo/SP/Brasil \\ moisesgalvao49@gmail.com
}

\section{Para citar- (ABNT NBR 6023:2018)}

FUSARO, Márcia; BATISTA, Moisés Galvão. Resenha. Eccos - Revista Cientifica, São Paulo, n. 58, p. 1-5, e20421, jul./set., 2021. Resenha. LUCCHESI, Marco. Cultura da Paz. Rio de Janeiro: Oficina Raquel, 2020. 204p. https://doi.org/10.5585/eccos.n58.20421.

Vivemos tempos desafiadores. Desde quando? Muito provavelmente desde que a história humana passou a ser registrada. Ou, quem sabe, bem antes disso. Conflitos, guerras, batalhas, jogos de interesse, epidemias, pandemias... Trágicos ecos humanos. Na educação não se faz diferente. Imensos desafios a exigir olhares cuidadosos. Persistentes. Leituras que nos eduquem para paz e a resiliência são, portanto, ainda mais bem-vindas em meio a essa tormenta vivida na atualidade. Nesse sentido educador para a paz é que nos interessa a delicadeza existencial, sobretudo educadora, presente na poética do livro Cultura da Paz, de Marco Lucchesi.

Mas antes de abordar propriamente o livro, equilibremos o jogo das evocações, pois há que se celebrar também os momentos afortunados vividos pela humanidade. Um dos mais notáveis: o surgimento e registro da poiesis. Surgimento este, pode-se arriscar dizer, inevitável em um planeta onde pulsa, como nascida do próprio contato com a ancestralidade da terra, a poesia dos cantos, das danças, das narrativas míticas. Lembre-se, ainda, o fulgurante surgimento do logos filosófico, seguido de tantas futuras conquistas científicas questionadoras da doxa. Tudo isso, seja nos momentos mais lamentáveis, ou nos mais afortunados, acompanhado de perto pela sábia expressão de grandes pensadores-poetas com alma de educadores a nos iluminar por caminhos inéditos e, igualmente, por outros tantas vezes já trilhados, mas que teimamos em repetir mesmo em face do prejuízo às causas humanas mais nobres. 
Marco Lucchesi é um desses pensadores-poetas-educadores. No seu caso particular: poeta-pensador-educador. O poeta sempre em primeiro lugar, antecipando o pensador e o educador. Em Cultura da Paz ressoam incontáveis vozes de outros tantos que, como ele, tiveram, e têm, a coragem de se indignar diante da vileza para pensar nossa existência circunstanciada por esta que, muito além de mera utopia, desde sempre se mostra como uma necessidade visceral em nosso planeta: a paz.

Em sua surpreendente liga poética avessa à repetição e amiga da singularidade, Lucchesi é incansável reinventor de si mesmo. A paz, que sua indignada voz insone reivindica com a máxima urgência, arrasta consigo ondas abismais de reflexões sobre o humano. Sim, a cultura da paz deveria ser para todos. É para todos, nos lembra com ênfase o poeta.

O prefácio anuncia já pelo título "Infância de Poeta: quase prefácio" o tom de incompletude em duração, próprio dos pontos brilhantes do passado sempre em reconstrução no presente sobre o qual Proust e outros grandes literatos tanto nos ensinam. O elegante posfácio assinado por Ana Maria Haddad Baptista arremata, em cuidadosa leitura, a erudição aliada à suntuosa poética em graus plurais da literatura de Lucchesi. De fato, a vasta erudição do poetapensador nunca corre o risco de se perder em meio ao labirinto das vozes referenciais ecoantes em sua prosa poética. Ao contrário, e para sedução definitiva do leitor de alma formada, para lembrar Clarice Lispector, também por ele evocada em dado momento, é justamente pela vastidão de sua erudição que Lucchesi mais encontra sua própria senda poético-ensaística. Não há subestimação do leitor. Ao contrário, segue implícita à leitura, como em toda sua obra, o convite à pesquisa de seus rizomáticos referenciais. E nisso se reconhece também o educador Marco Lucchesi.

Os ensaios de Cultura da Paz se reúnem em subtítulos suscitadores da imaginaçãoleitora: Locatários do Presente; Índice de Barbárie; Pentimento e Proporção; Corpo-Galáxia; Inquietude Semântica; Apolo e Tutuguri; Topologias; Fuga em Ré Menor. Ao longo de tais espessuras, palavra, aliás, recorrente em sua poética sempre a lidar com densidades, Lucchesi reafirma, incansável, quanto sempre vale a pena nos posicionarmos e lutarmos pela paz não restrita à mera utopia. E não caminha sozinho por essas espessas veredas.

A exemplo de Dante, que encontra em Virgílio um guia à altura de sua busca pela luz do paraíso e de Beatriz, Lucchesi se remete constantemente a apoiadores de peso. Adeptos, cada um à sua maneira, da mesma causa pela paz por meio da literatura e da cultura. Assim é que, pelos ecos poéticos de Lucchesi, ouvem-se também as vozes de Dante (gigante inspirador sempre a guiá-lo), Agostinho, Tomás de Aquino, Leonardo, Camões, Montaigne, Kant, 
Nietzsche, Cervantes, Dostoiévski, para se ficar somente com alguns nomes de um passado tão necessariamente evocado pelo poeta-pensador.

Artaud, Nise da Silveira, Umberto Eco, Haroldo de Campos, Remo Bodei, Teilhard de Chardin, Einstein, Jacques Monod, Prigogine dentre nomes do século XX, passando por outros tantos que, como ele próprio, representam, in memoriam ou in vitam, uma imortalidade literária legitimada pela Academia Brasileira de Letras (ABL): Machado de Assis, Eduardo Portela, Nelida Piñon, Ferreira Gullar, Ligia Fagundes Telles, Carlos Heitor Cony...

Ocupante da cadeira número 15 da ABL, anteriormente ocupada, entre outros, por Olavo Bilac, e que tem Gonçalves Dias por patrono, Lucchesi exerce, neste ano ainda tão desafiador de 2021, o quarto mandato seguido, por reeleição, à frente da presidência da ABL. De fato, muito do que se lê em Cultura da Paz parece nascido justamente dos devires em desafio desse exercício em que ele próprio se posiciona como um buscador da paz por meio da expansão humanizadora da cultura literária.

"Carta a um Jovem Preso" é dos ensaios mais tocantes que se pode ler em Cultura da Paz. Sobretudo por esses tempos em que se mostra vital, em termos de saúde planetária, nossa reconciliação com o humano, a natureza e a paz. Esse ensaio emociona não por algum índice de pietà. Longe disso. Mas pela dignidade humana com que Lucchesi compartilha, incondicionalmente, sua sábia erudição buscadora de paz e liberdade. Sua resposta à carta de um preso, mais do que conscientizar, educa-nos em momentos de abismais mergulhos em almapensamento:

Concordo: a literatura abre todas as celas, que são muitas e sutis, quando não invisíveis, dentro das quais vivemos, todos, sem exceção, mais ou menos conscientes da liberdade que precisamos conquistar. Não diminuo, apesar disso, um milímetro de sua dor e inquietação. A sua história acusa a ausência do Estado e o caminho áspero e solitário que o levou ao cárcere. Somos todos culpados, em certo grau, embora o artigo e a pena recaiam sobre o indivíduo. E aqui também nos solidarizamos um com o outro (p.35).

No primeiro conjunto de ensaios, reunidos sob o título de "Locatários do Presente", memórias fluem ao longo de páginas evocadoras de uma poética geográfica. Seja uma geografia imaginária, fio da memória a desfazer agendas físicas e virtuais recomeçadas no início de mais um ano, sejam as lembranças dos pais emigrados da Itália ao Brasil durante a Segunda Guerra Mundial. Passam, ainda, por essa geografia memorialista lembranças de visitas a Cusco (Peru), Nova Déli (Índia) e o Rio de Janeiro da queima de fogos do Ano Novo, onde é possível se encontrar os ares tanto da Bahia quanto da longínqua Beirute presentes na rua da Alfândega.

"Índice da Barbárie" é o título do segundo rol de ensaios. O tom se dá pela indignação do poeta-pensador perante a barbárie de ainda termos de conviver com situações indignas de 
aprisionamentos dos mais diversos tipos. Condições inaceitáveis de cárceres de corpos e almas, explícitas e implícitas, diante das quais Lucchesi se posiciona como incondicional defensor da liberdade. Seus argumentos evoluem com a propriedade de quem visita presídios na condição de educador pela voz da literatura e dos livros.

"Pentimento e proporção" celebra artistas do porte de Leonardo da Vinci, que o poeta descreve, entre incontáveis atributos revisitados aos 500 anos de sua morte, como gênio visionário para quem a poesia é pintura cega e a pintura é poesia muda (p.50). E segue o percurso ensaístico em que pintura e música, alinhavadas pela exatidão geométrico-matemática, ou pela criatividade insubordinada à precisão, são trazidas à baila passando por nomes como o do pintor italiano Guido Reni, dos brasileiros Israel Pedrosa, José Bechara e Cândido Portinari, para finalizar com a música do também brasileiro Francisco Mignone. Lucchesi não deixa de lamentar a tímida presença da arte nas escolas brasileiras, considerando como imperativo categórico recuperá-la para a cidadania (p. 56).

“Corpo-Galáxia" é viagem poética estelar que parte de lembranças dos saudosos Ferreira Gullar (também imortal da ABL), por ocasião de sua partida em 2016, passa pelo refino tradutório de Jorge Wanderley e chega ao poeta simbolista romeno Ştefan Petică. A escala obrigatória da viagem ocorre em Dante, seguindo em voo pela poesia da portuguesa Eugénia de Vasconcellos e da cabo-verdiana Vera Duarte Pina.

"Inquietude Semântica" saúda os nomadismos experimentais, aliados às bem-vindas inquietudes intelectuais, de Carlos Heitor Cony, Eduardo Portella e José Cândido de Carvalho. Montaigne é bússola referencial de inquietação textual do passado revigorada nas várias vozes ensaísticas evocadas até o presente, incluindo-se a do próprio Lucchesi. As obras monumentais dos italianos Dino Buzzati e Umberto Eco também são alvos das reflexões do poeta-pensador nesse quadrante ensaístico. $\mathrm{O}$ arremate de singularidade experimental fica por conta do derradeiro ensaio do segmento intitulado "Livros Fantasmas". Aposta machadiana-borgiana no desvelamento (marotamente nem um pouco confiável!) sobre a gênese de criação da obra Catálogo da biblioteca do excelentíssimo senhor marquês Umbelino Frisão, escrita "por um tal de Lúcio Marchesi”. Melhor não revelar mais detalhes sobre os segredos por trás da obra e do ensaio. Deixe-se ao leitor o prazer da descoberta.

“Apolo e Tutuguri” reúne somente dois ensaios, mas com uma densidade de infinitos. O primeiro é dedicado ao imenso poeta e ator francês Antonin Artaud, referência quando se fala em teatro e em experimentalismo poético existencial. Ao sondar a vastidão de Artaud, Lucchesi percorre quatro caminhos poético-reflexivos: O Teatro de Séraphin; O Poder da Imagem; O Infinito e o Peyotl; Teologias do Inconsciente. O filósofo italiano Remo Bodei surge 
no segundo momento, em suntuoso diálogo com Lucchesi. Veredas dialéticas trilhadas por literatura, filosofia, arte, ciência, orquestradas pela densa poética de pensamento e expressão de ambos.

"Topologias" adentra, mais uma vez, territórios reivindicadores de respeito e liberdade humana selados pela epígrafe de uma "aritmética da compaixão" (p. 135), que abre o segmento lembrando o poeta polonês Zbigniew Herbert. Começa-se, em altíssimo estilo, pela poética de vida em perpétua compaixão da dra. Nise da Silveira, definida nas palavras precisas de Lucchesi como "uma das glórias da ciência no Brasil" (p.137). O tema seguinte é a favela como lugar digno de representação social a ser alcançado pelas políticas públicas, pois "precisamos da dialética de Paulo Freire para o concerto urbano, com seus instrumentos legais" (p. 142). A memória dos livros e arquivos da Biblioteca e do Arquivo Nacional surgem a seguir, antecipando o que, no ensaio seguinte, será a celebração das memórias de Cartola e Pasolini em diálogos ativos com o presente. Despede-se essa sequência de ensaios com o adeus ao acadêmico Evaristo de Moraes Filho, imortal da ABL, que, na definição de Lucchesi, "foi dos pensadores mais refinados sobre a democracia no Brasil" (p.148).

O derradeiro conjunto de ensaios se reúne sob o título de "Fuga em Ré Menor". De teor mais autobiográfico, conduzem o leitor pelos caminhos da Vida Poética, com maiúsculas, de Marco Lucchesi. Seus discursos de posse na ABL, mais do que refinada literatura transposta a essas páginas reivindicadoras de paz, são ensinamentos sobre como é possível levar a cabo, apesar dos desafios, em seus mais variados graus, uma existência dedicada à literatura celebradora da Vida. Da Liberdade. Da Paz. 